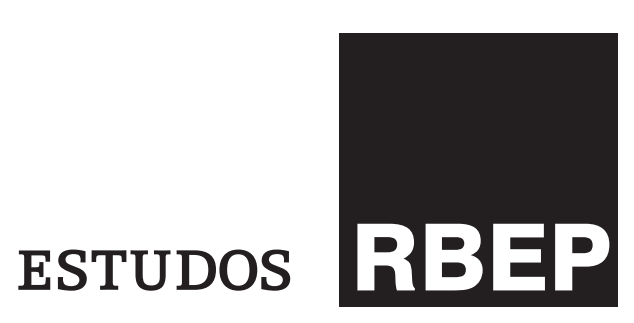

\title{
Anísio Teixeira e o Plano Nacional de Educação de 1962 - qualidade social na construção da pessoa humana e da sociedade
}

\author{
Márcia Helena Amâncio ${ }^{\mathrm{I}, \mathrm{II}}$ \\ Remi Castioni ${ }^{\mathrm{III}, \mathrm{IV}}$ \\ https://dx.doi.org/10.24109/2176-6681.rbep.102i262.4583
}

Prefeitura Municipal de Patos de Minas. Patos de

Minas, Minas Gerais, Brasil. E-mail: <lelenaproinfo@ gmail.com>; <https://orcid. org.0000-0003-4319-1866>

II Doutora em Educação pela Universidade de Brasília (UnB). Brasília, Distrito Federal, Brasil.

III Universidade de Brasília (UnB). Brasília, Distrito Federal, Brasil. E-mail: <remi@unb. br $>$; $<$ https://orcid. org/0000-0002-5459-3492>.

IV Doutor em Educação pela Universidade de Campinas (Unicamp). Campinas, São Paulo, Brasil.

\section{Resumo}

Este texto aborda o planejamento educacional concebido por Anísio Teixeira como relator do I Plano Nacional de Educação - PNE (1963-1970). O estudo tem como objetivo identificar as influências nacionais e internacionais que concorreram para a agenda do I PNE e compreender os sentidos de sua formulação e implementação no contexto em que foi gestado. Foi adotado como percurso metodológico o referencial do ciclo de políticas a partir de uma das suas dimensões. Para análise, foram selecionados estudos acadêmicos, documentos do acervo da Biblioteca Virtual Anísio Teixeira, do Memorial Darcy Ribeiro e referências bibliográficas. Seguindo nessa direção, verificou-se que o PNE de 1962 sintetiza a ideia de Anísio Teixeira de que a educação não é um privilégio e, ao contrário do que se apregoa, sua exequibilidade estava ancorada a uma estratégia de país, com recursos para a sua implementação. O plano foi incorporado pelo Plano Trienal do governo João Goulart. Sua efemeridade se deve mais à sua interrupção, em 1964, do que ao conceito de educação pública, defendido no planejamento das ações previstas.

Palavras-chave: Anísio Teixeira; planejamento educacional; Plano Nacional de Educação. 


\begin{abstract}
Anísio Teixeira and the National Education Plan of 1962: social quality of education in the construction of the human person and society
\end{abstract}

This particular text covers the educational planning conceived by Anísio Teixeira as the rapporteur of the $1^{\text {st }}$ National Educational Plan PNE (1963-1970). The study's main goal is to identify the national and international influences in favor of the $1^{\text {st }} P N E$ and to understand the senses of its formulation and implementation in the context in which it was managed. The reference of the policy cycle from one of its dimensions was adopted as a methodological approach. For analysis, academical studies, documents from the archive of Anísio Teixeira's Virtual Library, the Darcy Ribeiro Memorial and bibliographical references were selected. Following this direction, it was verified that the 1962 PNE synthetizes Anísio Teixeira's idea that education is not a privilege, and, contrary to what is preached, its feasibility was anchored to a country strategy, with resources for its implementation. The plan was incorporated by the Triennal Plan of João Goulart's government. Its ephemerality is due more to its interruption, in 1964, than to the concept of public education defended in the planned actions plan.

Keywords: Anísio Teixeira; educational planning; National Education Plan.

\title{
Resumen \\ Anísio Teixeira y el Plan Nacional de Educación de 1962: calidad social en la construcción de la persona humana y de la sociedad
}

Este texto aborda la planificación educativa concebida por Anísio Teixeira como relator del I Plan Nacional de Educación -PNE (1963-1970). El estudio tiene como objetivo identificar las influencias nacionales e internacionales que contribuyeron a la agenda del I PNE y comprender los significados de su formulación e implementación en el contexto en el que fue creado. Se adoptó como enfoque metodológico la referencia del ciclo de políticas a partir de una de sus dimensiones. Para el análisis, se seleccionaron estudios académicos, documentos del acervo de la Biblioteca Virtual Anísio Teixeira, del Memorial Darcy Ribeiro y referencias bibliográficas. Siguiendo esta dirección, se constató que el PNE de 1962 sintetiza la idea de Anísio Teixeira de que la educación no es un privilegio $y$, contrariamente a lo que se afirma, su viabilidad estaba anclada a una estrategia de país, con recursos para su implementación. El plan fue incorporado por el Plan Trienal del gobierno de João Goulart. Su fugacidad se debe más a su interrupción, en 1964, de que al concepto de educación pública, defendido en la planificación de las acciones previstas.

Palabras clave: Anísio Teixeira; planificación educativa; Plan Nacional de Educación. 


\section{Introdução}

A expressão e a síntese do pensamento de Anísio Teixeira, a ideia de que a educação não é privilégio, deram título a uma conferência proferida pelo educador baiano em 1953. Nessa conferência, posteriormente publicada em livro homônimo, datado de 1957, o pensador retomou uma série de temas e ideias tratadas por ele desde os anos de 1920, mas que, refletidas sob a perspectiva da sua trajetória, permitiram discutir os marcos e as vicissitudes da educação brasileira na década de $1950^{1}$.

Segundo o entendimento de Anísio Teixeira, o drama sobre o qual se assentava a educação no Brasil decorria da insistência de nossa tradição escolar em considerar a educação como um processo de preparo de alguns indivíduos para uma vida mais fácil e, em rigor, privilegiada. Porém, na medida em que o ensino não chegava a formar o "privilegiado", provocava "a deterioração progressiva deste ensino, sobretudo depois que passou ele a contar realmente com esmagadora frequência popular" (Teixeira, 1994, p. 50).

Dessa forma, o cenário educacional do Brasil seria fruto de uma perspectiva dualista da educação que, tendo em vista a formação de uma "elite de privilegiados", resguardava exclusivamente a esses uma educação de qualidade. As propostas de Anísio Teixeira para o combate à situação diagnosticada na conferência de 1953 tomariam corpo no Plano Nacional de Educação (PNE) elaborado em 1962, para o período de sete anos (1963-1970). Destaca-se que o próprio Manifesto dos Pioneiros da Educação Nova, de 1932, já denunciava esse dualismo (Azevedo et al., 2010). Trechos integrais das reflexões de Anísio foram incorporados à relatoria feita por Fernando de Azevedo. Há uma passagem explícita atribuída a Anísio no Manifesto:

[...] De fato, o divórcio entre as entidades que mantêm o ensino primário e profissional e as que mantêm o ensino secundário e superior, vai concorrendo insensivelmente, como já observou um dos signatários deste manifesto, "para que se estabeleçam no Brasil, dois sistemas escolares paralelos, fechados em compartimentos estanques e incomunicáveis, diferentes nos seus objetivos culturais e sociais, e, por isso mesmo, instrumentos de estratificação social" (Azevedo et al., 2010, p. 51).

Na biografia de Anísio Teixeira, seus embates sociais e seus postulados em defesa da escola pública e, especialmente, em defesa da qualificação desta escola são observados, especialmente, por duas pesquisadoras: Wanda Pompeu Geribello (1977) e Clarice Nunes (2000a, 2000b). Os estudos de Wanda revelam que duas temáticas foram fundamentais para a construção do pensamento de Anísio Teixeira: a realidade educacional brasileira e a questão de como o processo de educação poderia lançar luzes para planejar o desenvolvimento de uma nação (Geribello, 1977). Por outro lado, ao analisar a obra de Anísio como um todo, Nunes (2000a, p. 6) compreende que ela é:

[...] para além dos resultados, um nứcleo de reflexão que se abre incessantemente de forma original. E o sentido que dela fazemos, as representações que construímos e aonde palpitam os valores que abraçamos. 
É possível assegurar que sobre esse tema pouco se fala de uma das grandes obras de Anísio Teixeira: o I Plano Nacional de Educação, o PNE de 1963-1970. Se a organização e a aprovação do Plano foram atribuídas ao Conselho Federal de Educação (CFE), pela Lei no 4.024, de 20 de dezembro de 1961 (Lei de Diretrizes e Bases da Educação Nacional - LDB), coube ao conselheiro Anísio Teixeira oferecer subsídios para a distribuição dos recursos federais e das metas quantitativas e qualitativas para os três níveis de ensino da educação básica. ${ }^{2}$

Assumindo como referencial de análise o ciclo de políticas, o movimento da pesquisa caracterizou o contexto que influenciou a concepção de educação pública do pensamento anisiano e, em seguida, a própria formulação do PNE. Ball, Bowe e Gold (1992) apresentaram uma reformulação cuidadosa do referencial proposto pelo ciclo de políticas, descrevendo-o como contínuo e constituído por três contextos principais: o contexto de influência, o contexto da produção do texto e o contexto da prática. Esses contextos estão inter-relacionados, não têm uma dimensão temporal ou sequencial e não são etapas apenas lineares. Cada um deles apresenta arenas, lugares e grupos de interesse e cada um deles envolve disputas e embates. Em síntese, tais autores romperam com o conceito clássico do campo da ciência política no qual as fases da política são separadas e acontecem em etapas definidas. No caso da educação, tal separação contribui ignorando as disputas e os embates de projetos de sociedade e focalizam apenas "[...] a racionalidade do processo de gestão" (Mainardes, 2006, p. 49).

As políticas públicas são iniciadas e os discursos são construídos no contexto da influência. Os representantes da sociedade civil e da sociedade política disputam e conciliam o discurso que dá significado à política em consonância com a linguagem do público mais amplo. Estamos aplicando essa abordagem num momento de construção do Estado brasileiro e no desenrolar das políticas desenvolvimentistas que caracterizaram o segundo governo Vargas até o golpe de 1964. Parece-nos apropriado, mesmo para a época, considerar a sistematização de Ball, Bowe e Gold (1992) na perspectiva de que eles apresentam uma abordagem que não separa as etapas clássicas do ciclo e, sim, a sua construção. Importa, portanto, compreender o contexto que influenciou Anísio Teixeira na elaboração do I PNE. Afinal, todo pensamento é datado e intimamente correlacionado à experiência de vida de seu autor.

O texto está dividido em duas partes, além desta introdução e das considerações finais. Na primeira parte, selecionamos como objetivo identificar as influências nacionais e internacionais que concorreram para influenciar o I PNE. Para tanto, foi fundamental recolocar a proposta dentro do quadro histórico que tornou possível a sua formulação. Na segunda parte deste estudo, temos como objetivo observar o I PNE, procurando, assim, compreender os sentidos de sua formulação e a implementação no contexto em que foi gestado.

\footnotetext{
Pesquisas sobre a história do planejamento político educacional no Brasil marcam que o I PNE (1963-1970) pouco contribuiu para o tema, visto que afirmam que o documento se limita a um instrumento de aplicação dos recursos financeiros pelos entes federados. Diante de tais colocações, é preciso lembrar que a LDB (Lei $\mathrm{n}^{\circ} 4.024$ de 20 de dezembro de 1961) estabelece ao CFE a tarefa de elaborar as metas para aplicação dos fundos de aplicação financeira. Logo depois, "dentro dessas normas, deverá a Comissão de Planejamento de Educação (Copled), já organizada pelo Governo Federal, desenvolver e detalhar o Plano Nacional de Educação destinado a atingir as metas estabelecidas" (Brasil. MEC, 1962, p. 34).
} 


\section{O contexto educacional do Brasil na década de 1950/1960}

Em entrevista concedida à Odorico Tavares em 1952, Anísio Teixeira rememorou a própria vida. No esforço mnemônico a que se propôs, considerou que ela se dividia em "ciclos":

Velha crença costuma dividir a vida dos homens em ciclos de 5, 7 ou 9 anos. Os ciclos de minha vida parecem ser de 7. O primeiro, importante e invisível como as raízes, foi a minha infância, numa pequena e antiga cidade sertaneja, Caetité, no seio de uma família dividida entre o patriarcalismo em desaparecimento e o republicanismo ardente dos pioneiros da abolição e da República (Teixeira, 2002, p. 198).

O sétimo ciclo, contexto histórico datado por este estudo, é marcado pela permanência de Anísio Teixeira no âmbito do Ministério da Educação e Cultura (MEC), entre 1951 e 1964. Por 13 anos esteve à frente de importantes instituições ligadas ao MEC, acumulou cargos e incumbências que o colocaram num papel de destaque face às políticas públicas educacionais do Brasil. A saber: secretário-geral da Campanha de Aperfeiçoamento de Pessoal de Nível Superior (Capes) - 1951; diretor do Instituto Nacional de Estudos Pedagógicos (Inep) - 1952; diretor do Centro Brasileiro de Pesquisas Educacionais (CBPE) - 1955; presidente da Sociedade Brasileira para o Progresso da Ciência (SBPC) - 1955-1957-1958-1959; e reitor da Universidade de Brasília (UnB) - 1963-1964. Essas instituições foram responsáveis pela gestão de cerca de $80 \%$ do orçamento do MEC à época (Gouvêa, 2010) ${ }^{3}$.

Em 1962, Anísio Teixeira foi escolhido como membro do Conselho Federal de Educação, com um mandato de seis anos, tendo intensa participação na elaboração e na aplicação do referido Plano, o que será discutido mais adiante. Então, chegamos ao contexto da influência das políticas públicas na década de 1960. Nesse período, no Brasil, a situação sócio-econômico-política, comparada à situação educacional, remete ao fato de que o governo Juscelino Kubitschek (1956 e 1961) se caracterizou pela criação de uma política voltada para o desenvolvimento econômico do setor privado, sobretudo pelo contexto de influência externo de duas instituições, a Comissão Econômica para a América Latina (Cepal) e o Instituto Superior de Estudos Brasileiros (Iseb), em contexto nacional.

Castioni e Rocha (2014) destacam que o I PNE formulado por Anísio ocorreu na sequência dos trabalhos da Comissão de Administração do Sistema Educacional de Brasília (Caseb) em 1959, cujo encargo foi dado a ele pelo presidente Juscelino Kubitschek. Anísio, como membro da comissão deliberativa, ficou encarregado de elaborar o "Plano de Construções Escolares de Brasília", que veio a público na Revista Brasileira de Estudos Pedagógicos (Rbep).

Abordando o contexto histórico com maior amplitude, para Fazenda (1989), no governo Jânio Quadros (31 de janeiro de 1961 a 25 de agosto de 1961), o Brasil se encontrava com o estopim da bomba da ditadura aceso. Uma grave crise política foi deflagrada e a posse de João Goulart seria o desdobramento legal da renúncia de Jânio Quadros. Na visão da mesma 
autora, "a educação naquele governo apresentou-se como elementochave no desenvolvimento nacional" (Fazenda, 1989, p. 49). Nesse viés, ao adotar medidas de integração nacional e centralizar as decisões relativas à educação em geral, o governo João Goulart utiliza medidas de planificação educacionais respaldadas pela Carta de Punta del Este $^{5}$ e por decisões de nível mundial. Cabe ainda mencionar que aquela política foi marcada pela atuação de dois dos seis ministros, os da Educação e da Cultura: Darcy Ribeiro (1962-1963) e Júlio Sambaqui (1963-1964).

O CFE foi instalado em 12 de fevereiro de 1962, tendo como principal função assessorar o ministro da Educação e Cultura. Além disso, a sua instalação apoiou-se na Recomendação $\mathrm{n}^{\circ}$ 54, do Bureau Internacional da Educação Pública (1965), que propunha medidas para o planejamento da educação, bem como nas orientações dos organismos internacionais e das bases da Carta de Punta del Este, que defendiam a educação como instrumento para atingir o planejamento econômico e social e a elevação da cultura geral.

A LDB de 1961 (Lei no 4.024, de 20 de dezembro de 1961) determinava que a União despendesse recursos para a educação $0^{6}$. A referida lei instituiu ainda que os recursos federais destinados ao ensino primário, médio e superior seriam constituídos em parcelas iguais. Também estabeleceu ao CFE a competência de elaborar o PNE (Brasil, 1961). A relação entre a educação com padrões de qualidade e o desenvolvimento nacional exigiria do Estado um planejamento. Coube então a Anísio Teixeira essa tarefa.

\section{Plano Nacional de Educação (1963-1970) por dentro: os significados de suas formulações}

Com base na abordagem teórica do ciclo de políticas, no contexto de produção do texto, os textos (legais e oficiais), os pronunciamentos e os comentários são elaborados diante dos acordos e ajustes definidos no contexto de influência. É, portanto, o contexto de produção do texto que dá corpo a uma política educacional, que movimenta uma arena de produção de sentidos, os quais são disponibilizados e colocados em circulação por meio de textos legais, políticos, comentários formais ou informais sobre os discursos e os textos oficiais (Ball; Bowe; Gold, 1992).

Freitas (2013) argumenta que não se pode confundir sentido com significado. Para a autora, o sentido é inquieto, tem formação dinâmica, fluida, complexa, por incluir as circunstâncias sócio-históricas. Por outro lado, o significado é literal, explícito e fechado em si mesmo, unívoco. Assim, os sentidos do planejamento educacional não se limitam à sua função ou a um sentido preciso, nem são estáticos e imutáveis, pois adquirem novos significados no contexto da prática, envolvendo entidades políticas, sociais e seus atores.

Antes de seguirmos com as atividades do CFE na elaboração do PNE, é importante colocar em tela o relatório apresentado pela delegação brasileira na "Conferência sobre Educação e Desenvolvimento Econômico

\footnotetext{
Os países latino-americanos que se reuniram no Uruguai e assinaram a Carta de Punta del Este (1962) receberiam estrutura organizacional pelo Acordo de Cooperação Tripartite entre a Organização dos Estados Americanos (OEA), o Banco Interamericano de Desenvolvimento (BID) e a Comissão Econômica para a América Latina (Cepal), órgão das Nações Unidas. Por esse acordo, a OEA, através do Conselho Interamericano Econômico e Social (Cies), cumpriria a função de empreender estudos fundamentais e avaliar os planos de desenvolvimento nacional a longo prazo, submetidos pelos governos da região. Caberia ao BID canalizar os fundos destinados aos diversos projetos e, à Cepal, fornecer boa parte dos especialistas necessários aos novos programas de desenvolvimento econômico. A reunião extraordinária do Conselho Interamericano Econômico e Social em nível ministerial, realizada em Punta del Este, incorporou aos compromissos acima o "Plano Decenal da Educação da Aliança para o Progresso". Nesse documento, estavam as primeiras metas a serem alcançadas nos dez anos seguintes, adaptando todo o programa educativo aos interesses da industrialização, não só do Brasil, mas da América Latina, com exceção óbvia de Cuba. Uma leitura sobre as metas pode ser encontrada em Arapiraca (1982)

6 Art. 92 - A União aplicará, anualmente, na manutenção e no desenvolvimento do ensino, $12 \%$ (doze por cento), no mínimo, de sua receita de impostos e os Estados, o Distrito Federal e os Municípios, 20\% (vinte por cento), no mínimo (Brasil, 1961).
} 
e Social na América Latina", que teve lugar em Santiago do Chile, de 5 a 19 de março de 1962. De acordo com Horta (1982), a elaboração do relatório foi coordenada pelo Inep, que coordenava à época a elaboração das principais iniciativas da educação. Participou de sua elaboração o departamento econômico do Ministério do Interior, a Campanha Nacional de Aperfeiçoamento de Pessoal de Nível Superior (atual Capes) e o Serviço de Estatísticas da Educação e Cultura (Seec). Nesse ambiente, conforme abordaremos na análise do Plano, ao mesmo tempo que Anísio Teixeira e Darcy Ribeiro se ocupavam com a educação, Celso Furtado desenhou o planejamento para enfrentar os problemas sociais e econômicos. A concepção do economista e dos intelectuais da educação converge com o entendimento da educação, não somente essencial para o desenvolvimento, mas também como elemento para a construção da qualidade do fator humano. Para um amplo programa social, a educação deveria anteceder o investimento reprodutivo.

A educação interfere no tempo, e, melhorando-se a qualidade do fator humano, modifica-se por completo o quadro do país, abrindose possibilidades de desenvolvimento muito maiores. Não há país que tenha conseguido se desenvolver sem investir consideravelmente na formação de gente. (Furtado, C., 2007, p. 11).

De acordo com o relatório, para cumprir com suas atribuições na elaboração do Plano, o CFE deveria estar provido dos instrumentos técnico-científicos indispensáveis para o exercício de duas funções de planejamento. Com tais instrumentos, as ações previstas na LDB tomariam forma de planejamento e poder-se-ia evitar que fossem reduzidas a mais uma reforma do sistema educacional brasileiro. Em função dessa necessidade, os elaboradores do relatório solicitaram a criação de um centro de planejamento educacional como núcleo do Inep. Além disso, o centro poderia prestar assessoramento ao MEC na formulação da política educacional brasileira e adotar o planejamento educacional como norma básica de ação governamental (Conferência..., 1962). As propostas da delegação brasileira foram ao encontro das deliberações da Conferência da Educação em Santiago. Contudo, ainda de acordo com Horta (1982), o Centro de Planejamento Educacional, embora previsto no plano orientador da UnB e vinculado à Faculdade de Educação, não chegou a funcionar ${ }^{7}$.

Logo após assumir o MEC, Darcy Ribeiro submeteu o programa de emergência do MEC para aprovação do conselho de ministros. Aprovado em 26 de setembro de 1962, para aplicação até o mês de dezembro do mesmo ano, um auxílio financeiro a ser pago em três parcelas. A rápida aprovação do Programa de Emergência foi justificada pela grave situação educacional do País, revelada em estatísticas do documento ministerial. "O Programa de Emergência prepara, não só o Ministério de Educação, mas cada escola, as Secretarias de Educação de todos os Estados para a grande tarefa que é o Plano Nacional de Educação" (Brasil. MEC, 1962, p. 16).

Os dados do Instituto Brasileiro de Geografia e Estatística (IBGE), no ano de 1961, revelaram também a extensão do afunilamento na estrutura 
educacional estudantil: menos de 15\% da população estudantil do ensino primário passava para o ensino por nível; quase $2 \%$ da rede primária chegava ao ensino superior e apenas 0,5\% à pós-graduação. Em uma amostra de professores do ensino por nível, em 1955, 9\% encontravam-se diplomados em faculdades de Filosofia; $41 \%$ diplomados em nível superior e 50\% diplomados em nível médio, especialmente normalistas (Brasil. MEC, 1963). A estatística sinalizou três objetos que exprimem o contexto educacional no governo Jango: o debate da função da escola pública; os programas de alfabetização de adultos pelos movimentos sociais; e a questão do ingresso no ensino superior.

Com o objetivo de elaborar os planos de aplicação dos fundos nacionais de ensino primário, médio e superior, conforme determinado pela LDB, foi designada uma comissão especial formada por Anísio Teixeira, D. Cândido Padim, Brochado da Rocha e Almeida Júnior. O debate sobre o ensino iniciou com a sessão plenária de abril de 1962. Por compreender que a tarefa do CFE era estabelecer as "bases para elaboração de Planos de Educação destinados à aplicação dos fundos de ensino", os membros da comissão foram incumbidos de relatar aquele tema. No entanto, apenas Anísio o fez (Amâncio, 2017, p. 150) ${ }^{8}$.

Anísio Teixeira, em 1962, adverte que a ideia de "plano" não era recente no Brasil. Contudo, sempre encontrara viva resistência. Para Anísio, a razão disso decorreria do fato de que um planejamento deveria ser elaborado com obrigações bem determinadas e o "incidental e o parcial" desviavam os objetivos visados. Segundo o educador, isso ocorria no Brasil principalmente devido à "liberdade de caprichos e extravagâncias" a que se entrega o brasileiro, que "goza da liberdade de ser caprichoso" (Teixeira, 1962c). Postula ainda "[...] que a educação, como o cultivo da terra, as técnicas da indústria, os meios de cuidar da saúde não são assuntos de leis, mas de experiência e da ciência" (Teixeira, 1962c).

Diante do desafio de inserir a educação em um processo que aperfeiçoasse e estimulasse o País ao progresso, Anísio Teixeira considera primeiro ser necessário restabelecer o verdadeiro conceito de educação. Para que isso ocorra, devemos retirar-lhe o conceito de escola para o privilégio, regulada apenas pela lei e a burocracia formal.

A educação deve se caracterizar por um processo de cultivo e amadurecimento individual, "insusceptível de ser burlado", pois corresponde a um crescimento orgânico, humano, governado por normas científicas e técnicas, e não jurídicas, e a ser julgado sempre a posteriori e não pelo cumprimento formal de condições estabelecidas a priori. (Teixeira, 1962c).

No debate preliminar apresentado na sessão de abril de 1962, no CFE, anexo ao texto do PNE, Anísio reconhece o avanço da carta constitucional. Porém, reafirma a necessidade de um planejamento que otimize a aplicação dos recursos, coordene os empreendimentos e evite o desperdício do dinheiro público. Segundo a sua análise, dois princípios constitucionais governam a elaboração dos planos: a obrigatoriedade da educação primária e a gratuidade da educação ulterior à primária, para os que provarem a falta
8 Em anexo ao Plano

Nacional de Educação, de 1962, intitulado o Debate Preliminar (sessão de abril de 1962), observamos que $\mathrm{D}$ Cândido afirma que somente dois dias antes da reunião foi comunicado que deveria ser um dos relatores do tema, fato que o impediu de apresentar um trabalho escrito. Brochado da Rocha argumenta que seu papel na comissão seria de assessoria jurídica, portanto, preferiu aguardar a incidência do direito sobre esses fatos (Brasil, 1962 apud Amâncio, 2017). 
de recursos. Isso admite a possibilidade, pelo menos teórica, de o brasileiro ir à justiça para obter a educação a que tem direito. Naquela sessão do CFE, Anísio ratifica seu pensamento de que o direito à educação representa igualmente uma solução para a justiça social. Nas palavras de Rocha (2019):

\begin{abstract}
A compreensão é que o direito individual, se não estiver universalizado, torna-se um privilégio. Anísio soube interpretar muito bem essa asserção, ao insistir que, antes de se afirmar que a educação é um direito, tem-se de insistir que não pode se tornar um privilégio, senão não será um direito. Isso quer significar, também, que a educação não é simplesmente um direito de todos e um dever do estado, tal como está na nossa progressista Constituição de 1988, mas um direito de cada indivíduo, na democracia. A expressão direito de todos pode até parecer mais avançada, porém não o é, simplesmente porque a afirmação de que a educação é um direito da coletividade abre brecha para que a parte da elite contrária à educação pública possa se utilizar de certos estratagemas muito sutis para negar o direito individual à educação.
\end{abstract}

Para analisar o I PNE 1963-1970, adotamos a perspectiva teóricoconceitual de Bordignon (2014). Com base nela, consideramos que a finalidade do planejamento educacional consiste na qualidade social da educação, na pessoa humana e na sociedade. Vale dizer que a cidadania é parte integrante da nossa "utopia" educacional. Os caminhos, os meios e os modos de caminhar rumo aos objetivos colocados em pauta são dados pela concepção de educação adotada. Esses elementos não expressam apenas diretrizes para a educação, mas articulam interesses, projetam políticas e produzem intervenções sociais.

O desenho de um plano, baseado na concepção de educação adotada, é dado pelas metas a alcançar, as diretrizes a seguir e as estratégias da caminhada. As metas constituem desafios e compromissos dos agentes públicos e o controle social. As diretrizes estabelecem normas das políticas e oferecem os parâmetros para a ação. As estratégias definem os programas de ação dos agentes públicos para que sejam alcançadas as metas. No processo de elaboração, destacam-se: o diagnóstico, que implica o conhecimento da realidade da educação naquele momento e os elementos que a corroboram; a definição das metas, referenciada pela concepção de educação, na utopia da qualidade social e seu papel na construção da pessoa humana, e da sociedade que se deseja promover; e, finalmente, a definição das ações e dos processos, as estratégias da caminhada (Bordignon, 2014).

No Plano Nacional de Educação, o diagnóstico do conhecimento da realidade da educação e os elementos que a corroboram foram proporcionados pelo relatório apresentado pela delegação brasileira na Conferência sobre Educação e Desenvolvimento Econômico e Social na América Latina, entre os dias 5 e 19 de março de 1962, em Santiago. O relatório focalizou a situação demográfica e social do Brasil e o programa econômico do governo.

Em relação à definição das metas, o desenho do PNE e suas aplicações evidenciam que o trabalho foi dividido em duas partes ${ }^{9}$. A primeira, intitulada Plano Nacional de Educação, referente aos fundos nacionais de ensino primário, médio e superior, apresentando três metas quantitativas e quatro metas qualitativas para os níveis de ensino a serem colocadas em prática dentro de um prazo de oito anos: 
METAS QUANTITATIVAS. 1. ENSINO PRIMÁRIO, matrícula, até a quarta série, de $100 \%$ da população escolar de 7 a 11 anos de idade, e matrícula nas quinta e sexta, séries, de $70 \%$ da população escolar de 12 a 14 anos. [...] 2. ENSINO MEDIO, matrícula de 30\% da população de 11 e 12 a 14 anos nas duas primeiras séries do ciclo ginasial; matrícula de $50 \%$ da população escolar de 13 a 15 anos nas duas últimas séries do ciclo ginasial; e matrícula de $30 \%$ da população escolar de 15 a 18 anos nas séries do ciclo colegial. [...] 3. ENSINO SUPERIOR, expansão da matrícula até a inclusão, pelo menos, de metade dos que terminam o curso colegial. [...] METAS QUALITATIVAS. [...] 4. Além de matricular toda a população em idade escolar primária, deverá o sistema escolar contar, até 1970, com professores primários diplomados, sendo 20\% em cursos de regentes, $60 \%$ em cursos normais e $20 \%$ em cursos de nível pós-colegial. [...] 5. As duas últimas séries, pelo menos, do curso primário ( $5 .^{\mathrm{a}}$ e $6 .^{\mathrm{a}}$ séries) deverão oferecer dia completo de atividades escolares e incluir no seu programa o ensino, em oficinas adequadas, das artes industriais. [...] 6. O ensino médio deverá incluir em seu programa o estudo dirigido e estender o dia letivo a seis horas de atividades escolares, compreendendo estudos e práticas educativas. [...] 7. O ensino superior deverá contar, pelo menos, com 30\% de professores e alunos de tempo integral. (Brasil. MEC, 1962, p. 33-34).

As metas acima tinham por finalidade assegurar o estabelecido no artigo 93 da LDB/1961, bem como os compromissos internacionais assumidos pelo Brasil. Com isso, intentava-se a melhoria progressiva do ensino e o aperfeiçoamento dos serviços de educação. Subsequente às metas, o CFE estabeleceu as normas para a aplicação dos recursos do Fundo Nacional do Ensino. Dentro dessas normas, deveria a Comissão de Planejamento da Educação (Copled), já organizada pelo governo federal, desenvolver e detalhar o Plano Nacional de Educação destinado a atingir as metas estabelecidas (Brasil. MEC, 1962).

A segunda parte do documento trata da aplicação dos recursos do fundo nacional do ensino primário e da aplicação dos recursos do fundo nacional de ensino médio, no exercício de 1963, em obediência ao PNE. Com relação ao fundo nacional do ensino superior, como não havia recursos para distribuir, o CFE restringiu-se apenas às recomendações. Para distribuir o total de recursos, o conselho optou por uma perspectiva mais descentralizada, deixando para as unidades federadas a responsabilidade de aplicá-los.

Para Saviani (2014), Anísio arquitetou um procedimento engenhoso para a distribuição dos recursos federais com o cálculo do custo por aluno/ ano. Ele propôs uma equação matemática para o cálculo dos recursos que a União repassaria a cada unidade da Federação ${ }^{10}$. "Foi esse procedimento que inspirou a criação, em 1996, do Fundef, orientação que foi mantida com a substituição do Fundef pelo Fundeb em dezembro de 2006" (Saviani, 2014, p. 26).

Em entrevista concedida à revista O Cruzeiro, em novembro de 1962, Anísio Teixeira traça um panorama sobre a concepção de educação que referenciou a definição das metas do Plano Nacional de Educação e seu objetivo último, qual seja a qualidade social na construção da pessoa humana e da sociedade. Sobre a questão que versava sobre o sentido do PNE, esclarece Anísio, que o Brasil, naquele momento, estava em pleno processo de unificação e integração do corpo social em uma só sociedade
10 A interpretação de Anísio sobre o tema pode ser vista em Teixeira (1953). 


\footnotetext{
11 Dentro da documentação arrolada no Memorial Darcy Ribeiro, destacamos o documento, intitulado Memorandum, de caráter confidencial elaborado para subsidiar a reunião da Subcomissão dos Nove e encaminhado ao presidente JK em 23 de fevereiro de 1960. Daquela reunião surgiriam os temas para a agenda de visita do Presidente Eisenhower, no Brasil. Para os idealizadores do documento, as ações previstas para a educação poderiam ser viabilizadas na assistência financeira e nos métodos de ensino para um intenso programa de formação de técnicos para o desenvolvimento e para a luta contra o analfabetismo; de preferência através do Banco Interamericano. $\mathrm{O}$ esquema esboçado nos campos de ação teria impacto especialmente forte se aplicado, total ou parcialmente, em uma só região ou área caracterizada. O Nordeste do Brasil surge como prioridade (Documentos..., 1960).
}

nacional de indivíduos com direitos comuns. Diante disso, as tarefas dos responsáveis pela elaboração do planejamento educacional era:

[...] a incorporação das camadas ainda marginais da massa brasileira ao povo propriamente dito e a oferta a esse povo de oportunidades iguais de educação para a sua mobilização no empreendimento comum do desenvolvimento nacional [...]. (Teixeira, 1962b, p. 7).

Graças a isto, o plano elaborado pelo Conselho Federal de Educação pôde constituir-se mais que um plano pedagógico ou mesmo administrativo [...], a fim de poder inserir a escola no seio local e daí partir o esforço pela emancipação educacional de sua população. (Teixeira, 1962b, p. 1).

No que se refere à tarefa de integrar e conjugar o poder federal, o poder estadual e o poder municipal, Anísio chama a atenção para o fato de que o "espírito do Plano" era o da integração de todos os serviços públicos locais, municipais e estaduais, "na tarefa suprema e comum no Estado Democrático de oferecer a todos oportunidades iguais de educação" (Teixeira, 1962b, p. 2). Ao Estado cabia a liderança do processo por estar, segundo Anísio, mais emancipado das influências que ainda permaneciam em muitos municípios, do "velho espírito oligárquico e privatista que implica erradicar" (Teixeira, 1962b, p. 2). Os serviços de educação, organizados por municípios, seriam, simultaneamente, locais, estaduais e nacionais.

[...] sofrendo integralmente a influência das três ordens do governo, como são, aliás, os serviços de justiça e, na ordem material, os serviços rodoviários. Será isto que dará unidade a todo o plano [...], como organização política da nação, pela formação do cidadão brasileiro para sua plena eficiência social (Teixeira, 1962b, p. 2).

Dentro da lógica acima, cada estado organizaria o seu plano, embasado no plano de cada município e, de posse dele, é que se dirigiria ao governo federal para assinar o convênio de cooperação educacional e de assistência financeira e técnica. À União caberia oferecer assistência à elaboração dos planos estaduais e elaborar, de acordo com as normas do CFE, o seu plano de assistência financeira, de assistência técnica e de assistência política no setor dos projetos financeiros de empréstimos para a educação.

Anísio prossegue explicando que o I PNE tinha em vista a equalização das oportunidades educacionais para a população escolar de cada município. Por isso, partia da completa reabilitação da escola primária, base e fundamento de todo sistema escolar. Adverte ainda que os serviços educacionais citados acima constituiriam o conjunto do sistema escolar por estado, destinado a oferecer oportunidades de ensino em cada povoado, cada vila e cada cidade. Estas, por sua vez, seriam interligadas por meio de um sistema de bolsas, capaz de permitir à "criança pobre, mas bem-dotada", prosseguir nos estudos.

Sobre os ônus do I PNE, Anísio esclarece que seria impossível colocá-los sobre os ombros dos brasileiros, já pagadores de impostos. Em conformidade com os mecanismos já previstos pela Aliança para o Progresso (Alpro) ${ }^{11}$, as despesas correriam por meio de empréstimos, feitos pelo governo federal, tomados por 15, 20, 30, 40 anos. Esses recursos já estavam 
previstos no Plano Nacional e incluídos no custo por aluno. Com base nesse desenho, Anísio Teixeira vislumbrava um futuro no qual o PNE ampliaria não apenas as oportunidades educacionais, mas, também, oportunizaria o desenvolvimento de cada localidade tocada por ele.

Em relação à estrutura oferecida ao ensino secundário, Anísio a considerava supostamente propedêutica ao ensino superior. "Querendo tudo ensinar pouco ensina de cada coisa e, deste modo, falha em sua finalidade propedêutica, como falha - e aí pela sua própria natureza - na finalidade de cultura geral, que muitos lhe querem emprestar". Na sua visão, a estrutura organizacional de um curso secundário não poderia se destinar apenas a alguns, mas à grande maioria, senão a todos os jovens de uma nação moderna. "Por isso mesmo, impõe-se a modificação de sua finalidade e objetivos" (Teixeira, 1958, p. 1-2).

Quanto ao ensino superior, Anísio compreende que um dos mais sérios impasses do Brasil se encerrava no fato de que os instrumentos de decisão na vida nacional estavam "bloqueados aos capazes". Por esse motivo, também no ensino superior delineava-se outra batalha: "Para enfrentar esta batalha o planejamento educacional precisa absorver nas universidades o impulso dos grupos que querem lealmente implantar a reforma. Dessa forma, estará a estrutura universitária permanentemente fertilizada pela força renovadora de seus elementos de vanguarda" (Teixeira, 1962b, p. 9).

Finalmente, questionado se acreditava que o Plano seria mesmo executado, Anísio responde:

\begin{abstract}
Creio que sim. A necessidade de sua execução está na consciência de todos os legisladores que criaram a possibilidade do plano ser elaborado e as condições para ser realizado, dos órgãos responsáveis pela sua elaboração e pelo seu cumprimento diante da pressão das camadas cada vez maiores da população e pelo alargamento das oportunidades de formação de sua juventude para as tarefas do país em desenvolvimento. (Teixeira, 1962b, p. 9).
\end{abstract}

A competência da Copled ${ }^{12}$ era elaborar o Plano. Com esse objetivo, o documento foi encaminhado à comissão acompanhado de um ofício assinado por Anísio Teixeira. Um significado histórico do I PNE está em que, pela primeira vez (provavelmente a única até hoje), um plano de educação foi aprovado em nosso País para ser aplicado à risca, havendo um órgão especialmente encarregado de fazê-lo (a Copled), mediante o controle rigoroso de sua aplicação, do começo ao fim (Castioni; Rocha, 2014).

As pesquisas de Horta (1982) esclarecem que, ainda em setembro de 1962, menos de uma semana após o documento de base ter sido encaminhado à Copled, o Decreto no 1.422, de 27 de setembro de 1962, criou o cargo de ministro de estado extraordinário, responsável pelo planejamento. O decreto atribuía ao seu titular, o economista Celso Furtado, a função de dirigir e coordenar a elaboração, em cooperação com os órgãos pertinentes da administração, de um Plano Nacional de Desenvolvimento Econômico e Social, a ser submetido ao poder executivo (Brasil, 1962).

Diante de um cenário econômico que apresentava dificuldades no gerenciamento das contas públicas e dos contratos externos, em 30 de

\footnotetext{
12 De acordo com o parágrafo único do decreto que cria a Copled, como diretor do Inep, o secretário-geral dessa comissão era o próprio Anísio Teixeira.
} 
dezembro de 1962 foi anunciado um novo modelo de orientação da política econômica do governo. Elaborado pela equipe chefiada pelo ministro Celso Furtado, o Plano Trienal de Desenvolvimento Econômico e Social "tratava de articular o planejamento da economia com programas setoriais nas áreas da saúde, educação, transportes, recursos naturais, energia, petróleo, agricultura, indústria etc. Ao mesmo tempo, se procederia à negociação da dívida externa" (Furtado, R., 2011, p. 11). Em conformidade com a planificação trienal do governo João Goulart, conduzida por Celso Furtado, o I PNE foi subdividido, ficando a primeira parte para ser aplicada de 1963 a 1965.

No Plano Trienal, foram estabelecidos os objetivos básicos e os parâmetros da política de desenvolvimento para os três anos seguintes. No quarto objetivo, o governo se comprometeu com o fomento de políticas públicas educacionais, com o desenvolvimento tecnológico e com a saúde pública, buscando, além da melhoria dos padrões de vida, o progresso cultural. O planejamento educacional é apresentado como programa setorial e o texto reitera a aplicação dos recursos por meio da coordenação dos esforços federais, estaduais e municipais, nos termos do PNE, no período de três anos. Além disso, estabelece que o mesmo esforço deverá ocorrer nos cinco anos seguintes, com a aplicação de recursos mais substanciais do que aqueles garantidos pela legislação, até o ano de 1965, para a conquista das metas estabelecidas pelo PNE.

A plataforma de suas lutas pode ser ressaltada nas metas, quantitativas e qualitativas, a serem garantidas pelo poder público, no I PNE, e incorporálas ao Plano Trienal de 1963-1970. O programa delineado apresenta a "indicação das linhas pelas quais a União irá colaborar com os Estados e os Municípios no grande esforço comum para atingir certos objetivos mínimos, dentro dos próximos três anos". Esse esforço deverá ser continuado nos cinco anos seguintes para a conquista das metas estabelecidas pelo Plano Nacional de Educação (Brasil. MEC, 1963, p. 11).

Propunha, ainda, oferecer seis anos de educação primária a todos os brasileiros da zona urbana, ampliando a qualidade presente nos núcleos educacionais mais avançados que chegasse até os núcleos menos avançados. Isso envolveria o conhecimento da chamada educação rural como educação comum limitada pelas condições rurais. Em relação à educação média, oferecer oportunidade de educação ginasial a $40 \%$ da população da faixa etária de 12 a 15 anos e oportunidades de educação colegial a 20\% da faixa de 16 a 18 anos.

O programa de recuperação e aperfeiçoamento do magistério era amplo. Inicialmente, a criação dos centros de treinamento do magistério

[...] a serem mantidos pela União, procura-se institucionalizar o esforço pelo aperfeiçoamento do magistério primário e médio e criar, definitivamente, a figura do professor supervisor. Cada um destes supervisores terá a seu cargo o trabalho escolar até o máximo de dez classes primárias, cujos mestres serão por ele assistidos e treinados (Brasil. MEC, 1963, p. 14). 
Apresentando um adendo, Santos (2017) assegura que Furtado participou da comissão responsável por conduzir o planejamento de criação da Universidade de Brasília, o que lhe garantia uma ampla visão sobre as perspectivas da ciência e da tecnologia para o futuro do País. O mesmo autor tem como premissa que Darcy Ribeiro não oscilou diante da oportunidade política de unir forças entre a nova LDB, o PNE e o Plano Trienal como caminhos para o aprofundamento das reformas educacionais.

É preciso lembrar que, em nossa pesquisa, não encontramos no texto do Plano Nacional de Educação referência explícita à equalização de oportunidades educacionais para adultos. O Plano previa, ainda, a alfabetização, até 1970, de todas as crianças, adolescentes e jovens entre 7 e 23 anos. No entanto, a educação de adultos como um dos sérios problemas sociais e políticos na estrutura da educação brasileira preocupou as autoridades educacionais. A gestão de Júlio Sambaqui, último ministro da Educação e Cultura do governo Jango, foi marcada por iniciativas de incentivo às atividades culturais e educativas em diversas regiões do País.

Como se pode depreender da rememoração de Lyra (1996), nos idos de 1963, na cidade de Angicos, Rio Grande do Norte, estudantes, em sua maioria universitários, criaram círculos de cultura por meio de recursos do governo daquele estado, da Superintendência do Desenvolvimento do Nordeste (Sudene) e da Aliança para o Progresso ${ }^{13}$, e tornaram possíveis iniciativas de incentivo ao programa de alfabetização de adultos baseado no Método Paulo Freire. No dia 2 de abril de 1963, Jango e Aluízio Alves, governador do Rio Grande do Norte, estiveram presentes nas atividades de encerramento do Método Paulo Freire nas 40 horas da experiência de Angicos.

Ampliando o tratamento da questão, Fávero (2013) afirma que, nesse cenário, foi registrado um capítulo da luta contra o analfabetismo da população adulta, liderada por amplos setores da sociedade civil (igrejas, estudantes, profissionais liberais), que passaram a promover ações educativas bastante originais. Com isso, nasceram alguns dos movimentos mais expressivos da educação e cultura popular do Brasil. O autor ressalta também que esse movimento encontrou apoio dos ministros da Educação aproveitando a nova LDB (Lei $\mathrm{n}^{\circ} 4.024$, de 20 de dezembro de 1961) e, em particular, as perspectivas abertas pelo I PNE, possibilitando novas linhas de financiamento que vieram para favorecer experiências educativas e culturais com as camadas populares. Por conta disso, o I PNE acabou por viabilizar o Plano Nacional de Alfabetização, coordenado por Paulo Freire a cargo da Copled.

O instável governo de João Goulart não teve força política para implementar o Plano Trienal. Sem dúvida, todo esse movimento articulava-se às perspectivas abertas pelo momento histórico, cujas confluências iriam se entretecer na formulação do PNE. Também é certo que os princípios transformadores da realidade do sofrido povo brasileiro, mimetizado no sertanejo encravado na alma de Anísio, seriam apunhalados pelo golpe civil militar de 1964. Como alerta Carvalho (2005), mais uma vez, o significado do discurso sobre a educação foi "formar almas" e, com esse objetivo, a
13 Documentos recentes elucidaram melhor a colaboração dos Estados Unidos com os estados brasileiros no período do governo Jango e contribuíram para pavimentar o terreno para o golpe de 1964. A Aliança para o Progresso é um dos programas que viabilizou a oposição e preparou a ruptura institucional. Entre esses estudos, destaca-se o livro de Loureiro (2020). 
educação cívica do povo. Além disso, a consolidação do espírito nacional, para alcançar o desenvolvimento econômico e a grandeza do País (Carvalho, 2005). Todavia, os princípios para o planejamento educacional projetados por Anísio ainda persistem e permanecem nos inspirando nas linhas datilografadas por ele, mirando a redenção dos rincões do Brasil.

Assim desenhado, o Plano ampliaria as oportunidades educacionais, as construções escolares, as oportunidades de trabalho em cada localidade brasileira e na sede dos municípios, o que contribuiria para fixar muitos munícipes em seu próprio município, em vez de forçá-los a emigrar para as cidades onde o poder e as oportunidades se concentram. Esse seria um dos resultados da descentralização que mais beneficiaria a formação do País. Chegará o dia "em que os centros irão buscar nos municípios os elementos de valor de que precisarão, em vez de ter à sua porta a congestão de candidatos despreparados, por falta de oportunidades de experiência, que agora a aflige" (Teixeira, 1962b, p. 4).

\section{Considerações finais}

O PNE de 1962 sintetiza as batalhas de Anísio Teixeira num momento de importantes debates no Brasil. O I PNE, ao contrário do que se apregoa, esteve ancorado a uma estratégia de país e a uma ancoragem econômica. O Plano foi incorporado pelo Plano Trienal e passou a ser coordenado pelo economista Celso Furtado. Sua efemeridade deve-se mais à sua interrupção, em 1964, do que à sua qualidade no planejamento das ações. O texto perseguiu o contexto que influenciou a concepção da educação pública cunhada pelo educador baiano e analisou as influências nacionais e internacionais recebidas na definição das metas com relação à educação e ao planejamento racionalizado.

Com base nesses dados, foi possível observar o I PNE por dentro e compreender que a plataforma da estrutura educacional para o período de 1963 a 1970 indicava instituir um sistema contínuo e integrado de educação. As influências recebidas na definição da agenda para a educação e o planejamento racionalizado buscaram assegurar o direito à educação pública para todos, sem privilégios e superadas as divisões do passado entre educação geral e especial, humanista e científica, prática e teórica. Ademais, defendia um sistema de preparação do magistério, com candidatos possuidores da educação geral ministrada pelos estados, formando, assim, a força de trabalho do sistema escolar. O Plano idealizado por Anísio demonstrava uma visão extremamente, ampla das opções político-pedagógicas, e mais: da noção de cidadania. É nesse sentido que nele se expressa um planejamento capaz de garantir o direito à educação pública.

Ora, se a educação como direito significa um progresso a ser duramente perseguido numa sociedade capitalista, a negação da educação como privilégio, que é o sentido cultural dado à educação dentro da história brasileira, é um desafio maior ainda. Anísio enfrentou-o tanto no diagnóstico da educação do Brasil, em Educação não é privilégio (1953), quanto na 
elaboração do I PNE. Todavia, o Plano foi abortado pelos militares em 1964. Nesse mesmo ano, a gestão do planejamento educacional transferiu-se dos educadores para os tecnocratas e, nesse cenário, em termos organizacionais, o Ministério da Educação ficou subordinado ao Ministério do Planejamento, cujos atores dirigentes e técnicos tinham como formação acadêmica as Ciências Econômicas.

Contudo, nos dias atuais, mais de 60 anos após a "avaliação diagnóstica" proposta em Educação não é privilégio, a análise de Anísio Teixeira acerca da educação brasileira, infelizmente, permanece desconcertantemente atual. A despeito dos marcos regulatórios da educação, expressos por meio da legislação, nosso ensino continua assentado sobre bases desiguais, as quais, por sua vez, refletem a profunda desigualdade social do País. Apesar de tal incômoda constatação, é preciso lembrar que o pioneirismo do I PNE sustentou os recursos do excepcional trabalho de alfabetização, que deu justa notoriedade internacional a Paulo Freire e aos princípios e contribuições contidos naquele Plano, incluídos no atual PNE (2014-2024), como se fossem originais. Seguimos com Anísio Teixeira na batalha por uma educação pública que deixe de ser privilégio para alguns, entendida como um direito social para a construção da pessoa humana e da sociedade.

\section{Referências}

AMÂNCIO, M. H. As batalhas de Anísio Teixeira: análise do contexto de influência do I Plano Nacional de Educação. 2017. 204 f. Tese (Doutorado em Educação) - Faculdade de Educação, Universidade de Brasília, Brasília, DF, 2017.

ARAPIRACA, J. O. A USAID e a educação brasileira: um estudo a partir de uma abordagem crítica da teoria do capital humano. São Paulo:

Editora Cortez, 1982.

AZEVEDO, F. et al. Manifesto dos pioneiros da Educação Nova (1932) e dos educadores (1959). Recife: Editora Massangana, 2010. (Coleção Educadores).

BALL, S. J.; BOWE, R.; GOLD, A. Reforming education \& changing schools: case studies in policy sociology. London: Routledge, 1992.

BORDIGNON, G. Caminhar da educação brasileira: muitos planos, pouco planejamento. In: MARTINS, A. M.; SOUZA, D. B. (Org.). Planos de educação no Brasil: planejamento, políticas, práticas. São Paulo: Edições Loyola, 2014. p. 29-53.

BRASIL. Lei $\mathrm{n}^{\circ}$ 4.024, de 20 de dezembro de 1961. Fixa as diretrizes e bases da educação nacional. Diário Oficial da União, Brasília, DF, 27 dez. 1961. Seção 1, p. 11429. 
BRASIL. Decreto do Conselho de Ministros $\mathrm{n}^{\circ} 1.422$, de 27 de setembro de 1962. Dispõe sobre as atribuições do Ministro de Estado extraordinário responsável pelo planejamento e dá outras providências. Diário Oficial da União, Brasília, DF, 28 set. 1962. Seção 1, p. 10147.

BRASIL. Instituto Nacional de Estudos Pedagógicos (Inep). Conferências Internacionais de Instrução Pública: recomendações (1934-1963). [Rio de Janeiro]: Inep, 1965. Disponível em: <http://www.dominiopublico.gov. br/download/texto/me002529.pdf>. Acesso em: 27 set. 2021.

BRASIL. Ministério da Educação (MEC). Plano Nacional de Educação. Brasília, DF: MEC, 1962.

BRASIL. Ministério da Educação (MEC). Plano Trienal de Educação (1963-1965). Brasília, DF: MEC, 1963.

CARVAlHO, J. M. Forças Armadas e política no Brasil. Rio de Janeiro: Jorge Zahar Editor, 2005.

CASTIONI, R.; ROCHA, J. A. L. O golpe militar de 1964 e a interrupção do I Plano Nacional de Educação - a UnB e a contribuição de Anísio Teixeira. Jornal da Ciência Notícias, Rio de Janeiro, n. 4941, 28 abr. 2014. Disponível em: <http://jcnoticias.jornaldaciencia.org.br/17-ogolpe-militar-de-1964-e-a-interrupcao-do-i-plano-nacional-de-educacaoa-unb-e-a-contribuicao-de-anisio-teixeira-2/>. Acesso em: 23 set. 2021.

CONFERENCIA de Santiago: I. Resolução Al - extensão e melhoria da educação em face do desenvolvimento econômico e social. Revista Brasileira de Estudos Pedagógicos, Rio de Janeiro, v. 38, n. 87, p. 55-57, jul./set. 1962.

DOCUMENTOS reservados para uso do Grupo de Trabalho encarregado de preparar a reunião do Comitê dos Nove. In: MEMORANDUM:

operação pan-americana, pedidos, petróleo, políticas públicas. Brasília, DF: [s. n.], 1960.

FÁVERO, O. Paulo Freire: primeiros tempos. Em Aberto, Brasília, DF, v. 26, n. 90, p. 47-62, jul./dez. 2013.

FAZENDA, I. C. A. Educação no Brasil nos anos 60: o pacto do silêncio. São Paulo: Edições Loyola, 1989.

FREITAS, M. T. A. Identidade e alteridade em Bakhtin. In: DE PAULA, L.; STAFUZZA, G. (Org.). Círculo de Bakhtin: pensamento interacional. 3. ed. Campinas: Mercado das Letras, 2013. v. 3. p. 183-199.

FURTADO, C. Em busca de um novo modelo: reflexões sobre a crise contemporânea. São Paulo: Paz e Terra, 2007. 
FURTADO, R. F. A. O Plano Trienal e o Ministério do Planejamento. Rio de Janeiro: Contraponto, 2011.

GERIBELLO, W. P. Anísio Teixeira: análise e sistematização de sua obra. São Paulo: Atlas, 1977.

GOUVÊA, F. C. F. Os sete encontros capitais do intelectual Anísio Teixeira. In: ENCONTRO NACIONAL DA ANPUH-RIO MEMÓRIA E PATRIMONIO, 14., 2010, Rio de Janeiro. Anais... Rio de Janeiro: Editora da Universidade Federal do Estado do Rio de Janeiro, 2010.

HORTA, J. S. B. Liberalismo, tecnocracia e planejamento educacional no Brasil. São Paulo: Editora Cortez, 1982.

LOUREIRO, F. P. A aliança para o progresso e o Governo João Goulart (1961-1964): ajuda econômica norte-americana aos estados brasileiros e a desestabilização da democracia no Brasil pós-guerra. São Paulo: Editora Unesp, 2020.

LYRA, C. As quarenta horas de Angicos: uma experiência pioneira de educação. São Paulo: Editora Cortez, 1996.

MAINARDES, J. Abordagem do ciclo de políticas: uma contribuição para a análise de políticas educacionais. Educação \& Sociedade, Campinas,

v. 27, n. 94, p. 47-69, jan./abr. 2006.

NUNES, C. Anísio Teixeira: a poesia da ação. Bragança Paulista: Editora Universitária São Francisco, 2000a.

NUNES, C. Anísio Teixeira entre nós: a defesa da educação como direito de todos. Educação \& Sociedade, Campinas, v. 21, n. 73, p. 9-40, dez. 2000b.

REUNIÃO DE CONSULTA DOS MINISTROS DAS RELAÇÕES EXTERIORES DA ORGANIZAÇÃO DOS ESTADOS AMERICANOS (OEA), 8., 1962, Punta del Este. Actas... Punta del Este: OEA, 1962. Disponível em: <https://dialnet.unirioja.es/descarga/articulo/2048393.pdf>.

Acesso: 27 set. 2021.

ROCHA, J. A. L. Breve história da vida e morte de Anísio Teixeira: desmontada a farsa da queda no fosso do elevador. In: SEMINÁRIO NACIONAL DE FILOSOFIA DA EDUCAÇÃO E PRAGMATISMO, 2., 2019, Teresina. Anais... Teresina: Programa de Pós-Graduação em Filosofia da Universidade Federal do Piauí, 2019.

SANTOS, L. A. O caminho da razão e da esperança: o pensamento social de Celso Furtado: desenvolvimento, planejamento e educação no Brasil. Educação em Revista, Marília, v. 18, n. 1, p. 73-92, jan./jul. 2017. 
SAVIANI, D. O Manifesto dos Pioneiros da Educação Nova de 1932 e a questão do Sistema Nacional de Educação. In: CUNHA, C. et al. O Sistema Nacional de Educação: diversos olhares 80 anos após o Manifesto. Brasília, DF: Ministério da Educação, 2014. p. 15-29.

TEIXEIRA, A. Sôbre o problema de como financiar a educação do povo brasileiro. Revista Brasileira de Estudos Pedagógicos, Rio de Janeiro, v. 20, n. 52, p. 27-42, 1953.

TEIXEIRA, A. O ensino secundário. Boletim Informativo Capes, Rio de Janeiro, n. 66, p.1-2, maio 1958.

TEIXEIRA, A. Plano de construções escolares. Revista Brasileira de Estudos Pedagógicos, Rio de Janeiro, v. 35, n. 81, p.195-199, jan./mar. 1961.

TEIXEIRA, A. Bases preliminares para o plano de educação referente ao Fundo Nacional de Ensino Primário. Revista Brasileira de Estudos Pedagógicos, Rio de Janeiro, v. 38, n. 88, p.97-107, out./dez. 1962a.

TEIXEIRA, A. [Entrevista dada ao "Cruzeiro" em novembro de 1962]. Cruzeiro, Rio de Janeiro, 1 dez. 1962b. Disponível em: <http://docvirt. com/docreader.net/docreader.aspx?bib =AT_prodInte\&pasta $=\mathrm{AT} \% 20$ pi\%20Teixeira,\%20A.\%201962.11.00>. Acesso em 24 set. 2021.

TEIXEIRA, A. Relatório em Debate preliminar: sessão de abril de 1962. In: BRASIL. Ministério da Educação (MEC). Plano Nacional de Educação. Brasília, DF: MEC, 1962c. p. 59-63.

TEIXEIRA, A. Educação não é privilégio. Organizado e comentado por Marisa Cassim. 5. ed. Rio de Janeiro: Editora da Universidade Federal do Rio de Janeiro, 1994.

TEIXEIRA, A. Hierarquia para os problemas da educação. [Entrevista concedida a] Odorico Tavares, 1952. In: ROCHA, J. A. L. (Org.). Anísio em movimento: a vida e as lutas de Anísio Teixeira pela escola pública e pela cultura no Brasil. Brasília, DF: Senado Federal, 2002. p. 195-206.

Recebido em 6 agosto de 2020.

Aprovado em 20 de maio de 2021. 